\title{
Beneficial haemodynamic effects of insulin in chronic heart failure
}

\author{
W A Parsonage, D Hetmanski, A J Cowley
}

\begin{abstract}
Objective-To characterise the central and regional haemodynamic effects of insulin in patients with chronic heart failure.

Design-Single blind, placebo controlled study.

Setting-University teaching hospital.

Patients-Ten patients with stable chronic heart failure.

Interventions-Hyperinsulinaemic euglycaemic clamp and non-invasive haemodynamic measurements.

Main outcome measures-Change in resting heart rate, blood pressure, cardiac output, and regional splanchnic and skeletal muscle blood flow.

Results-Insulin infusion led to a dose dependent increase in skeletal muscle blood flow of 0.36 $(0.13)$ and $0.73(0.14) \mathrm{ml} / \mathrm{dl} / \mathrm{min}$ during low and high dose insulin infusions $(\mathrm{p}<0.05$ and $\mathrm{p}<0.005 v$ placebo, respectively). Low and high dose insulin infusions led to a fall in heart rate of 4.6 (1.4) and 5.1 (1.3) beats/min ( $\mathrm{p}<0.05$ and $\mathrm{p}<0.005 v$ placebo, respectively) and a modest increase in cardiac output. There was no significant change in superior mesenteric artery blood flow.

Conclusion-In patients with chronic heart failure insulin is a selective skeletal muscle vasodilator that leads to increased muscle perfusion primarily through redistribution of regional blood flow rather than by increased cardiac output. These results provide a rational haemodynamic explanation for the apparent beneficial effects of insulin infusion in the setting of heart failure. (Heart 2001;85:508-513)
\end{abstract}

Keywords: blood flow; heart failure; insulin; muscle

Chronic heart failure is characterised by cardiac dysfunction, abnormalities of the peripheral circulation, and activation of neurohumoral mechanisms. There is likely to be a complex dialogue between these systems that ultimately leads to the clinical syndrome of heart failure. It has been suggested that insulin resistance may also be important in the pathophysiology of heart failure. ${ }^{12}$

Insulin resistance is usually shown by diminished hypoglycaemic action of insulin and it is believed that abnormalities of glucose handling at the cellular level account for its deleterious effects in cardiovascular diseases. These abnormalities may be particularly important in cardiac and skeletal muscle of patients with heart failure.

Insulin has other properties that may be important. It has been shown to cause peripheral arteriolar vasodilatation in normal healthy subjects. ${ }^{3}$ This effect is attenuated in patients with type II diabetes and hypertension. ${ }^{45}$ It has been suggested that the failure of insulin mediated vasodilatation is in part responsible for the insulin resistance associated with these conditions. Little is known, however, about the aetiology of insulin resistance or about the integrity of insulin mediated vasodilatation in chronic heart failure.

Peripheral blood flow is redistributed in heart failure: blood flow to the coronary and cerebral circulations is preserved at the expense of blood flow to other tissues. Reduced skeletal muscle blood flow is a major determinant of exercise tolerance and functional impairment in heart failure. ${ }^{67}$ Blood flow to other vascular beds such as the gut is less important. The mechanism of action of any agent that can reverse this abnormal redistribution of blood flow is therefore of considerable interest. Measurement of regional blood flow is therefore useful in assessing mechanisms that control the circulation in heart failure and the effects of treatment.

The purpose of this study was to evaluate the central and regional haemodynamic effects of insulin in a group of patients with chronic heart failure.

\section{Patients and methods}

PATIENTS

Ten male patients aged $54-82$ (mean 69) years with chronic heart failure were studied. All had mild to moderate heart failure (New York Heart Association functional class II-III) and were ambulatory outpatients. Heart failure was caused by ischaemic heart disease in six patients and dilated cardiomyopathy in the remaining four. All had an ejection fraction measured echocardiographically of $<45 \%$ or left ventricular end diastolic diameter of $>6 \mathrm{~cm}$. All were taking diuretics and a mean daily dose of furosemide of $80 \mathrm{mg}$ (range $40-160 \mathrm{mg}$ ). Nine were taking angiotensin converting enzyme (ACE) inhibitors and the 10 th patient was taking a long acting nitrate but no patients were being treated with $\beta$ blockers. All had been taking stable medication for at least four weeks. No patient was taking any treatment that affects glucose metabolism and none had another condition known to affect insulin sensitivity. All patients had normal fasting glucose (range $3.1-5.7 \mathrm{mmol} / \mathrm{l}$ ) and 

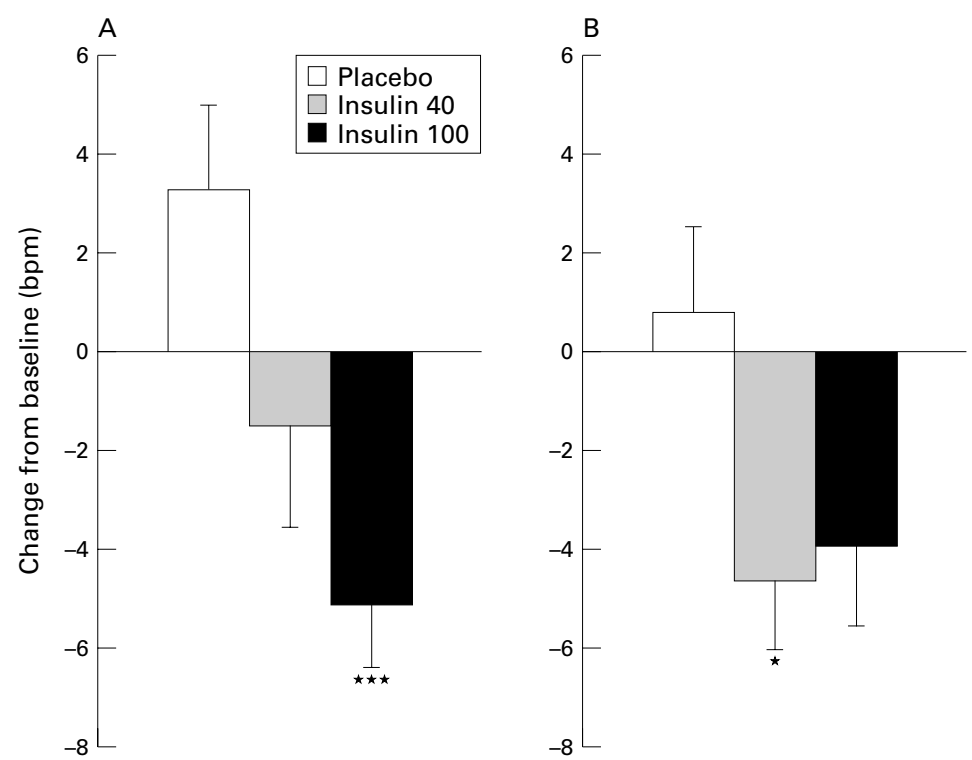

Figure 1 Change in heart rate (ANOVA $p=0.004)$. In this and figs 2-6, Insulin 40 and Insulin 100 refer to measurements taken during insulin infusions of 40 and 100 $\mathrm{mU} / \mathrm{m}^{2} / \mathrm{min}$, respectively, after (A) 30 minutes and (B) 60 minutes. ANOVA refers to analysis of variance for repeated measures that was used to compare the effect of insulin doses with placebo. Symbols refer to post hoc t tests comparing each dose of insulin infusion with placebo at each time point. ${ }^{\star} p<0.05,{ }^{\star *} p<0.01,{ }^{\star *} p<0.005$.
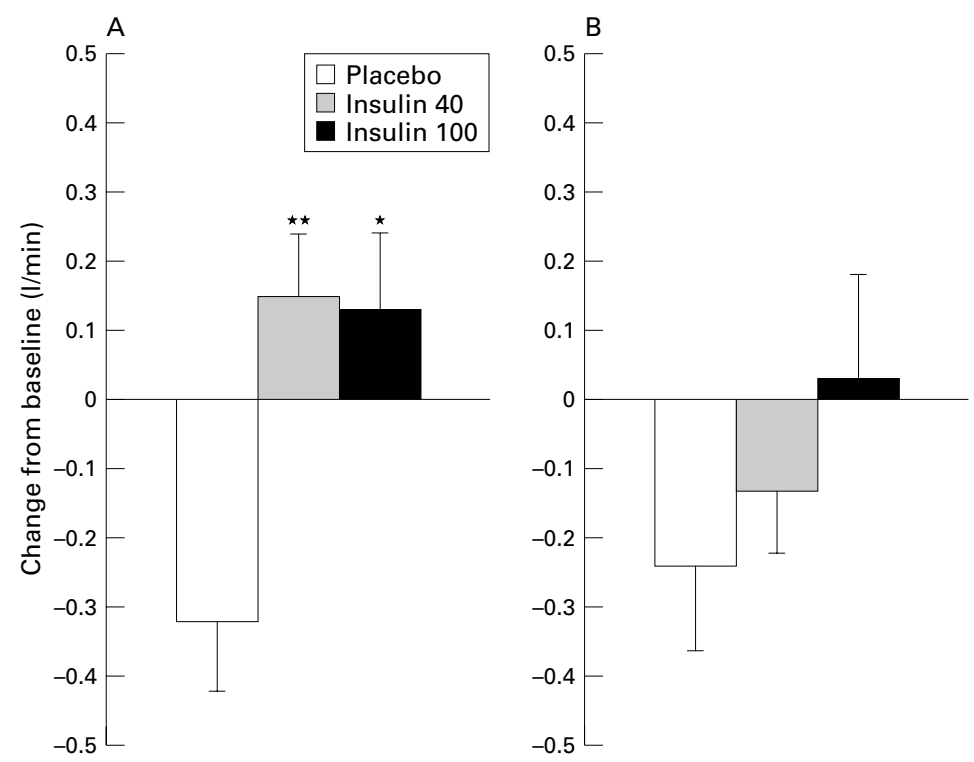

Figure 2 Change in cardiac output (ANOVA $p=0.025$ ). For key to symbols see fig 1 caption.

glycosylated haemoglobin (range 4.8-5.9\%) within the normal, non-diabetic range for the hospital.

\section{METHODS}

The patients were studied on two occasions in a temperature controlled laboratory $\left(23-24^{\circ} \mathrm{C}\right)$ at 8 am after an overnight fast and having omitted their usual drugs that morning. One day served as a control day and the other was the test day; the order of these was randomised.

HYPERINSULINAEMIC EUGLYCAEMIC CLAMP

Patients were studied in the supine position after 30 minutes' rest. The left hand was placed in a chamber with air circulating at $50-60^{\circ} \mathrm{C}$ to arterialise the venous blood and an 18 gauge cannula was inserted retrogradely into a vein on the dorsum of the hand. A second 18 gauge cannula was inserted anterogradely into a vein in the antecubital fossa of the same arm for infusion of insulin and glucose. Following a priming infusion, soluble insulin (Human Actrapid, Novo Nordisk, Crawley, UK) was infused at a rate of $40 \mathrm{mU} / \mathrm{m}^{2} / \mathrm{min}$ for 90 minutes and then increased to $100 \mathrm{mU} / \mathrm{m}^{2} / \mathrm{min}$ for a further 90 minutes. These doses of insulin were calculated to produce a steady state plasma insulin concentration of approximately 100 and $250 \mathrm{mU} / 1$, respectively. Blood sugar concentration was measured every five minutes and $20 \%$ glucose was infused at a variable rate to maintain blood sugar concentrations at the fasting, baseline concentration. This method of hyperinsulinaemic euglycaemic clamp has been described in detail elsewhere. ${ }^{8}$ On the control day the procedure was similar but normal saline was infused and repeated haemodynamic measurements were made for 90 minutes only.

HAEMODYNAMIC MEASUREMENTS

Haemodynamic variables were measured at rest at baseline and after 30 and 60 minutes of the first dose of insulin and then after 30 and 60 minutes of the second dose. On the control day haemodynamic measurements were made after 30 and 60 minutes of the placebo infusion.

Heart rate was monitored continuously and blood pressure measured by auscultation in the right arm.

\section{Cardiac output}

Cardiac output was measured non-invasively using the indirect Fick principle of monitoring respiratory gases with a mass spectrometer. Carbon dioxide was used as the indicator. Carbon dioxide production is calculated from minute ventilation and mixed expired carbon dioxide concentration. The partial pressure of carbon dioxide in pulmonary venous (systemic arterial) blood is derived from end tidal carbon dioxide concentration and the partial pressure in mixed venous blood is obtained following a rebreathing manoeuvre. These three variables can then be used to solve the Fick equation. The technique has been validated against thermodilution.'

Forearm blood flow

Forearm blood flow was measured in the right arm by venous occlusion plethysmography using mercury in Silastic strain gauges. The coefficient of variation for this technique in our laboratory is $11.5 \% .^{10}$

\section{Superior mesenteric artery blood flow}

Superior mesenteric artery flow was measured by transcutaneous Doppler ultrasound using a Diasonics Prisma system (Diasonics International, Les Ulis, France). The vessel was identified by ultrasound and the sample volume of the pulsed Doppler system was adjusted to the size of the vessel being interrogated. Doppler spectral analysis was recorded with the patients' breath held in midinspiration. Mean velocity was calculated from at least 10 Doppler waveform complexes. Vessel diameter was calculated from a mean of four values. Measurements and Doppler signals were recorded from the 


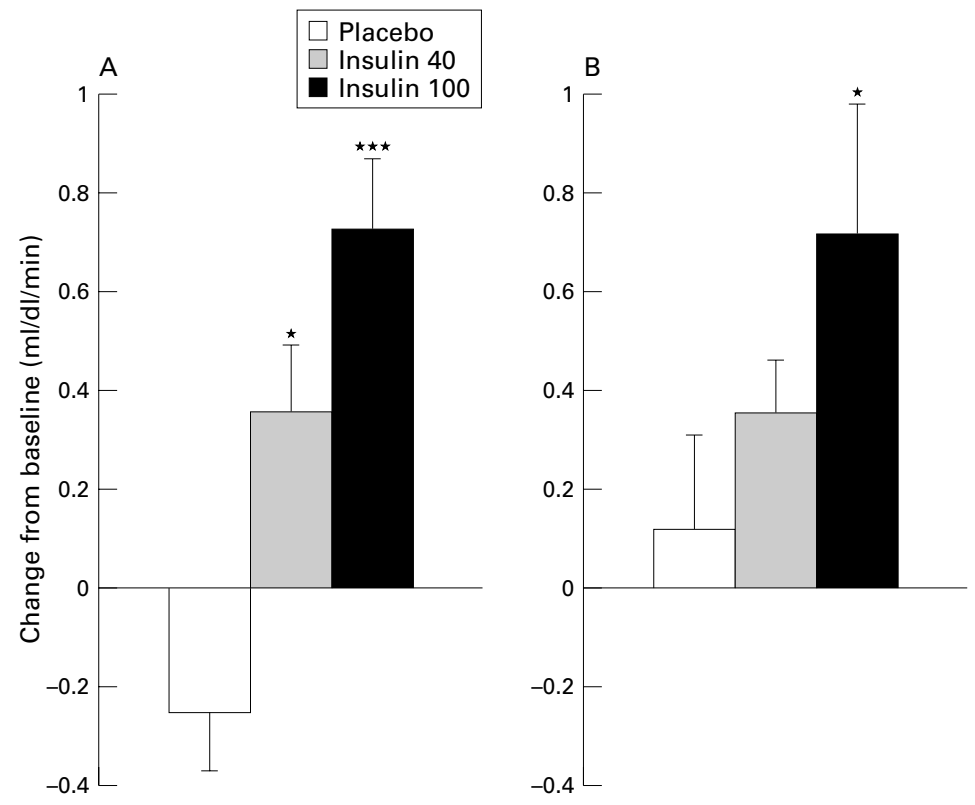

Figure 3 Change in forearm blood flow (ANOVA $p<0.001$ ). For key to symbols see fig 1 caption.
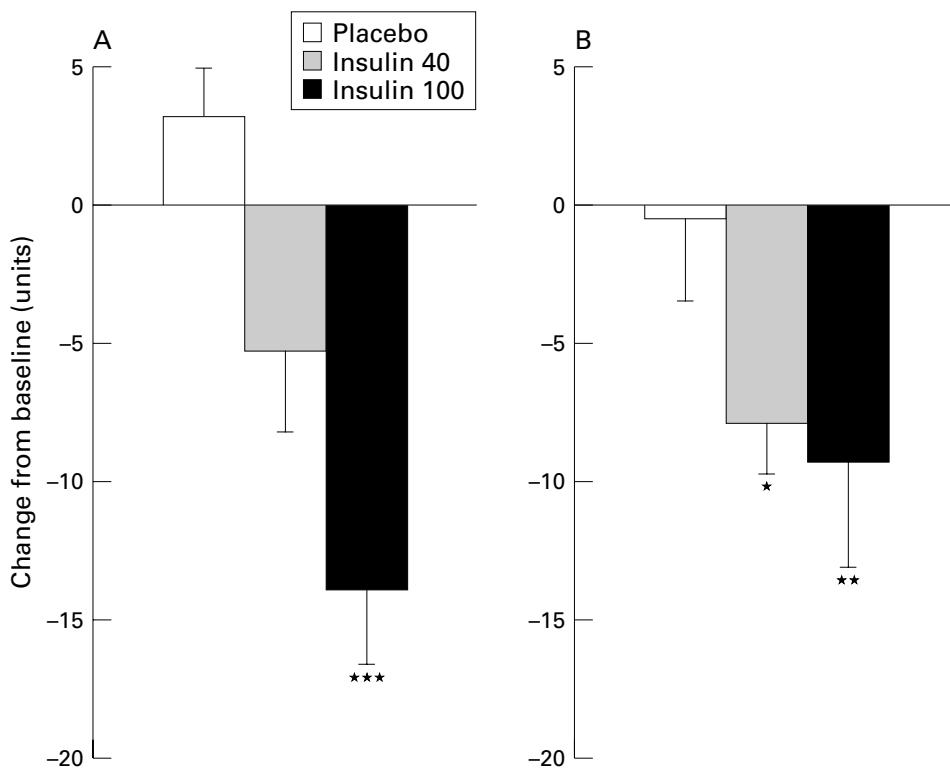

Figure 4 Change in forearm vascular resistance $($ ANOVA $p=0.001)$. For key to symbols see fig 1 caption.

proximal portion of each vessel. Blood flow was calculated by the machine's in-built software according to the following equation:

$\pi$ (vessel diameter $/ 2)^{2} \times$ mean velocity

The coefficient of variation of this technique in our laboratory is $<6 \%{ }^{11}$

\section{Vascular resistance}

Vascular resistance in arbitrary units for the superior mesenteric and forearm vascular beds was calculated using the formula: vascular resistance $=$ (mean arterial pressure/blood flow) $\times 100$.

\section{Biochemical measurements}

Arterialised blood was sampled at baseline and every 30 minutes during the experiment for measurement of plasma insulin and catecholamines. Blood was collected and allowed to clot in plain tubes before being spun at $2000 \mathrm{rpm}$ in a centrifuge for 20 minutes. The supernatant was stored in plain tubes at $-80^{\circ} \mathrm{C}$ for subsequent analysis. Insulin was measured by solid phase radioimmunoassay (Diagnostic Products Corp, Los Angeles, USA). In our laboratory this method has an intra-assay coefficient of variation of $7.0 \%$ and interassay coefficient of variation of $10.4 \%$. Plasma noradrenaline (norepinephrine) was measured by high performance liquid chromatography with electrochemical detection after extraction. The intra-assay and interassay coefficients of variation were $6.2 \%$ and $8.5 \%$, respectively.

\section{STATISTICAL ANALYSIS}

All results are expressed as mean (SD). Baseline values for haemodynamic variables on each visit were compared by paired $t$ tests. To examine the effect of the insulin infusion on haemodynamic variables, changes from baseline were calculated for measurements at each time point. Analysis of variance for repeated measures was calculated using the three insulin doses (placebo, low dose, and high dose) as a within subject factor. Where analysis of variance suggested a significant effect of the insulin infusion, post hoc paired $t$ tests were done to compare each insulin dose with placebo. A probability value of $p<0.05$ was considered significant.

\section{ETHICAL STANDARDS}

The local ethics committee approved the study and all patients gave written, informed consent.

\section{Results}

There were no significant differences in any of the haemodynamic or metabolic variables on the two study days. The mean baseline plasma insulin concentration was 14 (1) $\mathrm{mU} / 1$ on the control day and 14 (3) $m U / 1$ on the study day. Mean insulin concentration during the placebo infusion was 19 (2) mU/l. The mean plasma concentration of insulin rose to 103 (5) $\mathrm{mU} / 1$ during the infusion of $40 \mathrm{mU} / \mathrm{m}^{2} / \mathrm{min}$ and 241 (13) $\mathrm{mU} / 1$ during the infusion of $100 \mathrm{mU} / \mathrm{m}^{2} / \mathrm{min}$.

\section{HAEMODYNAMIC MEASUREMENTS}

Heart rate and blood pressure

Figure 1 shows the changes in heart rate on the control day and the study day. There was no difference in baseline heart rate on the control day, 62 (3) beats/min, and on the study day, 64 (4) beats/min. In response to the low dose insulin infusion heart rate fell by a maximum of 4.6 (1.4) beats $/ \mathrm{min}(\mathrm{p}<0.05 v$ placebo) and by a maximum of 5.1 (1.3) beats/min during the high dose infusion $(\mathrm{p}<0.005 v$ placebo). Mean arterial pressure fell in response to insulin by 5.5 (1.5) $\mathrm{mm} \mathrm{Hg}$ ( $\mathrm{p}<0.005 v$ placebo) during the low dose infusion and 6.9 (2.2) $\mathrm{mm} \mathrm{Hg}(\mathrm{p}<0.01 v$ placebo) during the high dose infusion.

\section{Cardiac output}

Figure 2 shows the values for cardiac output. There was no difference in baseline cardiac output on the control, $2.9(0.2) 1 / \mathrm{min}$, and 

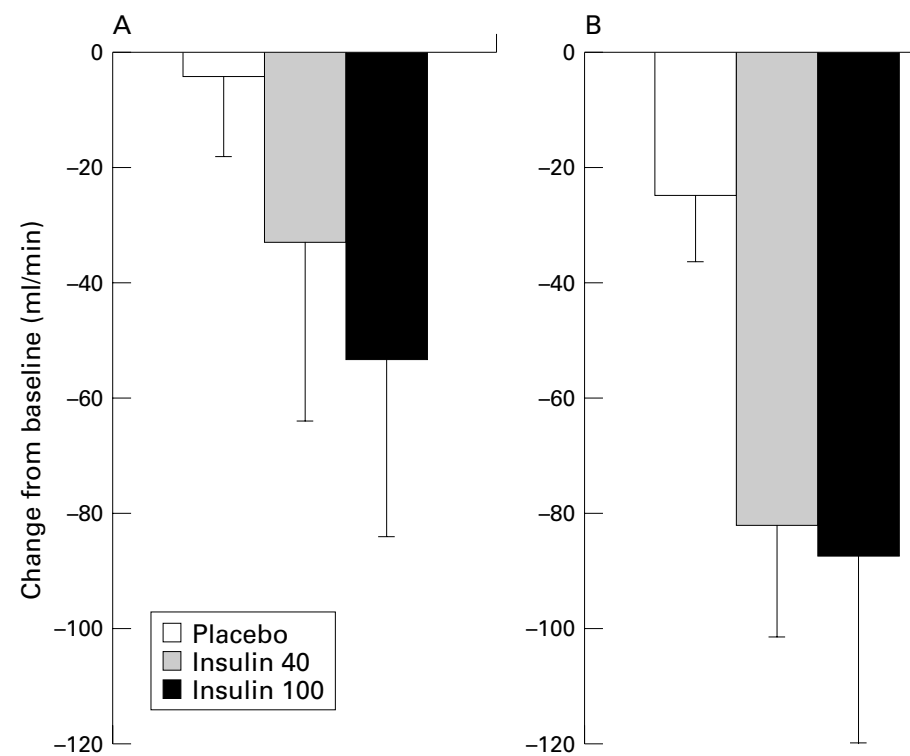

Figure 5 Change in superior mesenteric flow $($ ANOVA $p=N S)$. For key to symbols see fig 1 caption.
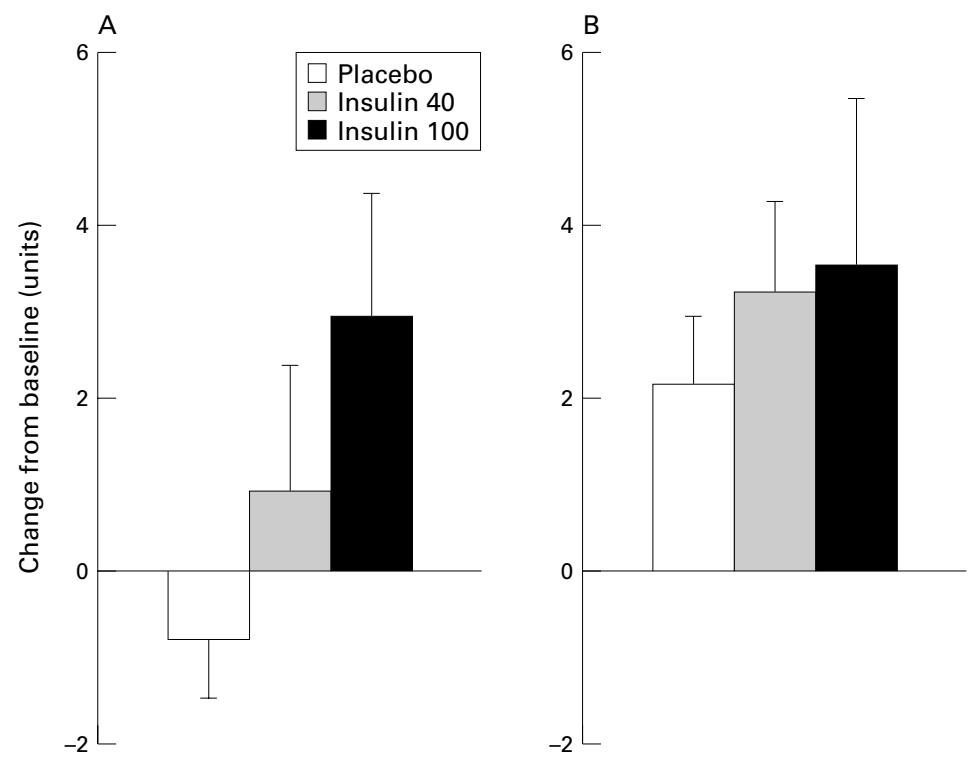

Figure 6 Change in superior mesenteric vascular resistance $(A N O V A p=N S)$. For key to symbols see fig 1 caption.

study days, $2.8(0.3) \mathrm{l} / \mathrm{min}$. Insulin led to a modest increase in cardiac output by a maximum of $0.15(0.09) \mathrm{l} / \mathrm{min}(\mathrm{p}<0.01 v$ placebo) during the low dose infusion and 0.13 (0.11) $1 / \mathrm{min}(\mathrm{p}<0.05 v$ placebo) during the high dose infusion.

Forearm blood flow

The changes in forearm blood flow are shown in fig 3. Baseline values were similar on the control day, $2.07(0.18) \mathrm{ml} / \mathrm{dl} / \mathrm{min}$, and on the study day $2.37(0.12) \mathrm{ml} / \mathrm{dl} / \mathrm{min}$. Insulin infusion had a highly significant effect on forearm blood flow compared with placebo $(p<0.001$ for analysis of variance). Forearm blood flow increased by $0.36(0.13) \mathrm{ml} / \mathrm{dl} / \mathrm{min}$ after 30 minutes of the low dose infusion $(\mathrm{p}<0.05 v$ placebo) and to $0.73(0.14) \mathrm{ml} / \mathrm{dl} / \mathrm{min}$ after 30 minutes of the high dose infusion $(\mathrm{p}<0.005 v$ placebo).
Figure 4 shows the changes in forearm vascular resistance. It decreased in response to both the low and the high dose infusions of insulin ( $p=0.001$ for analysis of variance).

Superior mesenteric artery blood flow

Figures 5 and 6 show the changes in superior mesenteric artery haemodynamics. Superior mesenteric vascular resistance rose and superior mesenteric blood flow fell during the experiment. There was a non-significant trend towards a greater fall in splanchnic blood flow during the insulin infusion $(p=0.145$ for analysis of variance).

PLASMA CATACHOLAMINES

Baseline plasma noradrenaline was 2.49 $(0.09) \mathrm{nmol} / 1$ on the control day and 2.49 (0.08) $\mathrm{nmol} / \mathrm{l}$ on the study day. There was no significant difference in the noradrenaline concentrations during the placebo and insulin infusions ( $p=0.734$ for analysis of variance).

\section{Discussion}

This study has shown that insulin has important and possibly unique central and peripheral haemodynamic effects in patients with chronic heart failure. It improved limb, and therefore skeletal muscle, blood flow by causing vasodilatation in the forearm vascular bed. There was a trend towards a reduction in blood flow to the gut that was probably secondary to the increased skeletal muscle blood flow and is a favourable redistribution of peripheral blood flow. Furthermore, a fall in heart rate and only a modest increase in cardiac output accompanied these changes. Insulin infusion had a negligible effect on sympathetic nervous system activity measured in terms of plasma noradrenaline concentrations.

Reduced blood flow to skeletal muscle has been shown to be a major determinant of exercise capability of patients with chronic heart failure. ${ }^{612}$ Agents such as ACE inhibitors and phosphodiesterase inhibitors increase blood flow to skeletal muscle and tend to improve exercise capability. ${ }^{73}$ ACE inhibitors have systemic vasodilatory properties without direct inotropic activity and have been shown to be of benefit in all grades of chronic heart failure. ${ }^{14}{ }^{15}$ In contrast drugs such as the phosphodiesterase inhibitors improve muscle blood flow in part by increasing cardiac output by their inotropic activity and have consistently been shown to worsen survival. ${ }^{16}$ Therefore, if skeletal muscle blood flow can be increased by local vasodilator action without major direct effects on cardiac output or sympathetic nervous system activity, then there should be no detrimental effect on mortality. Furthermore, if this vasodilatation is selective for the skeletal muscle vascular bed and is associated with a reduction in and redirection of blood flow from less important vascular beds such as the gut this would be of added value. The changes we have described occur at doses of insulin chosen to produce physiological plasma concentrations - the low dose and supraphysiological concentrations. At physiological concentrations insulin causes selective skeletal 
muscle vasodilatation and is associated with advantageous redistribution of peripheral blood flow. It appears to be unique in this respect.

The reduction in heart rate is interesting. In normal volunteers heart rate tends to increase with insulin probably because of increased sympathetic nervous activity. ${ }^{17}$ In our experiment insulin had no effect on plasma noradrenaline concentrations compared with placebo. The beneficial reduction in heart rate we observed possibly occurs because patients already have a high sympathetic tone and the vasodilator effects of insulin reduce this sympathetic drive. However, the relatively low mean resting heart rate, in the absence of $\beta$ blockade, in this cohort suggests that sympathetic activation at baseline was not particularly notable. An alternative explanation for the fall in heart rate would be a hitherto unrecognised effect of insulin on the parasympathetic system. Plasma noradrenaline concentration is an insensitive measure of changes in sympathetic activity. Further studies of autonomic activity by means of more robust methods such as microneurography in the face of insulin infusion in a similar cohort of patients would be of considerable interest.

Baseline measurements suggest that the study group had significantly impaired left ventricular function with reduced ejection fraction and low cardiac output. The mean resting cardiac output of approximately $3 \mathrm{l} / \mathrm{min}$ is lower than might be expected in patients with only moderate symptoms of heart failure and may be an underestimate. The study group was, however, older than most groups with heart failure in previous studies using invasive haemodynamic measurements and this may be a contributing factor to the low resting cardiac output. Our method of non-invasive measurement of cardiac output has been well validated and widely used, and is, we believe, robust. Since there was a modest increase in cardiac output in the face of a fall in heart rate, by extrapolation there must have been an increase in stroke volume during the insulin infusion. This may result from altered loading conditions on the heart caused by a reduction in systemic vascular resistance but this hypothesis must be confirmed by further, probably invasive, studies of central haemodynamics.

Insulin resistance has been identified as a component of the neurohormonal disturbance associated with chronic heart failure. ${ }^{12}$ Resistance to the metabolic action of insulin leads to a state of chronic overproduction of endogenous insulin to maintain normal blood glucose concentrations. It has been suggested that this state of hyperinsulinaemia may have beneficial haemodynamic effects in patients with chronic heart failure. This has been supported by a correlation between insulin resistance and skeletal muscle blood flow. Our results support this finding by confirming the integrity of insulin's vascular action in patients with chronic heart failure. However, little is known about the effect of chronic hyperinsulinaemia on muscle function during exercise and this remains an area for further study.
Regardless of the importance of endogenous overproduction of insulin our results raise fascinating questions about the use of exogenous insulin infusion in the management of patients with heart failure.

Insulin infusions have been used in the past to treat severe heart failure although this approach has never been subjected to a controlled trial and the mechanism of action has never been investigated in detail. ${ }^{18} \mathrm{~A}$ beneficial role for insulin infusion in patients with severe left ventricular dysfunction following cardiopulmonary bypass has also been proposed. ${ }^{19}$ Glucoseinsulin-potassium infusion following acute myocardial infarction was advocated in the 1960s but has never gained widespread acceptance. Interest in this treatment has been rekindled by a favourable meta-analysis and by the randomised, controlled DIGAMI (diabetes mellitus insulin-glucose infusion in acute myocardial infarction) trial, which elegantly showed the beneficial effect of early insulin treatment in diabetic patients with acute myocardial infarction. ${ }^{20}{ }^{21}$ Discussion of these studies has largely centred on the metabolic effects of glucose, insulin, and potassium infusions.

The beneficial effects of insulin in these settings have been assumed to come from a protective effect on myocardial metabolism. We have shown that in patients with chronic heart failure insulin is a selective peripheral vasodilator with a modest effect on cardiac output. Insulin has no effect on sympathetic nervous system activity and leads to a reduction in heart rate. Our results show that insulin has significant haemodynamics effects that may conceivably influence the outcome of patients with heart failure or acute myocardial infarction. Further studies focusing on the haemodynamic actions of insulin in the setting of severe decompensated heart failure, acute myocardial infarction, and cardiac surgery would be of great interest.

This study was funded by a grant from the Special Trustees of University Hospital, Nottingham, UK.

1 Paolisso G, De RS, Marrazzo G, et al. Insulin resistance and hyperinsulinemia in patients with chronic congestive heart failure. Metab Clin Exp 1991;40:972-7.

2 Swan JW, Walton C, Godsland IF, et al. Insulin resistance in chronic heart failure. Eur Heart f 1994;15:1528-32.

3 Baron AD, Steinberg HO, Chaker $\mathrm{H}$, et al. Insulin-mediated skeletal muscle vasodilation contributes to both insulin sensitivity and responsiveness in lean humans. $\mathcal{F}$ Clin Invest 1995;96:786-92.

4 Laakso M, Edelman SV, Brechtel G, et al. Impaired insulinmediated skeletal muscle blood flow in patients with NIDDM. Diabetes 1992;41:1076-83.

5 Baron AD, Brechtel-Hook G, Johnson A, et al. Skeletal muscle blood flow: A possible link between insulin resistance and blood pressure. Hypertension 1993;21:129-35.

6 Wilson JR, Martin JL, Schwartz D, et al. Exercise Wilson JR, Martin JL, Schwartz D, et al. Exercise
intolerance in patients with chronic heart failure: role of intolerance in patients with chronic heart failure: role of
impaired nutritive flow to skeletal muscle. Circulation 1984; 69:1079-87.

7 Cowley AJ, Rowley JM, Stainer K, et al. Effects of captopril on abnormalities of the peripheral circulation and respiratory function in patients with severe heart failure. Lancet 1984;ii: $1120-4$

8 DeFronzo RA, Tobin JD, Andres R. Glucose clamp technique: a method for quantifying insulin secretion and resistance. Am f Physiol 1979;237:E214-23.

9 Cowley AJ, Stainer K, Murphy DT, et al. A non-invasive method for measuring cardiac output: the effect of Christmas lunch. Lancet 1986;ii:1422-4.

10 Kearney MT, Stubbs TA, Cowley AJ, et al. A carbohydrate meal attenuates the forearm vasoconstrictor response to lower body subatmospheric pressure in healthy young adults. Clin Auton Res 1997;7:285-91.

11 Stubbs TA, Macdonald IA. Within- and between-day variability in transcutaneous Doppler ultrasound measurements of superior mesenteric artery blood flow (SMABF) in the fasted state. Physiol Meas 1998;19:181-7. 
12 Zelis R, Longhurst J, Capone RJ, et al. A comparison of regional blood flow and oxygen utilization during dynamic forearm exercise in normal subjects and patients with congestive heart failure. Circulation 1974;50:137-43.

13 Cowley AJ, Stainer K, Fullwood L, et al. Effects of enoximone in patients with heart failure uncontrolled by captopril and diuretics. Int f Cardiol 1990;28:52-3.

14 Swedberg K, Idanpaan-Heikkila U, Remes J, et al. Effects of enalapril on mortality in severe congestive heart failure Results of the cooperative north Scandinavian enalapril survival study (CONSENSUS). $N$ Engl F Med 1987;316: 1429-35.

15 Yusuf S. Effect of enalapril on survival in patients with reduced left ventricular ejection fractions and congestive heart failure. N Engl f Med 1991;325:293-302.

16 Cowley AJ, Skene AM. Treatment of severe heart failure: quantity or quality of life? A trial of enoximone. Enoximone investigators. Br Heart f 1994;72:226-30.
17 Anderson EA, Hoffman RP, Balon TW, et al. Hyperinsulinemia produces both sympathetic neural activation and vasodilation in normal humans. F Clin Invest 1991;87: 2246-52

18 Allison SP, Morley CJ, Burns-Cox CJ. Insulin, glucose, and potassium in the treatment of congestive heart failure. $B M \mathcal{F}$ 1972;iii 675-8.

19 Svedjeholm R, Huljebrant I, Hakanson E, et al. Glutamate and high-dose glucose-insulin-potassium (GIK) in the treatment of severe cardiac failure after cardiac operations. Ann Thorac Surg 1995;59:S23-30.

20 Fath-Ordoubadi F, Beatt KJ. Glucose-insulin-potassium therapy for treatment of acute myocardial infarction: an overview of randomized placebo-controlled trials. Circulation 1997;96:1152-6.

21 Malmberg K, Ryden L, Efendic S, et al. Randomized trial of insulin-glucose infusion followed by subcutaneous insulin tion (DIGAMI study): effects on mortality at 1 year. $f$ Coll Cardiol 1995;26:57-65.

\section{IMAGES IN CARDIOLOGY}

\section{Acute mitral valve dysfunction: a new case of leaflet escape}

Leaflet escape is a rare cause of heart valve prosthesis dysfunction. We present a new case occurring five years after mitral valve replacement. A 45 year old man was transferred to the emergency unit of our hospital with acute pulmonary oedema which appeared following a violent episode. He had a history of rheumatic valvulopathy. In 1995 he had undergone mitral valve replacement with a $29 \mathrm{~mm}$ Edwards Tekna (Baxter, USA) bileaflet prosthesis, and aortic valve replacement with a $23 \mathrm{~mm}$ St Jude Medical (SJM, USA) prosthetic heart valve. On admission he presented severe orthopnoea; blood pressure was $110 / 60 \mathrm{~mm} \mathrm{Hg}$ in both arms, pulse was 120 beats/min, and respiratory rate was 22 breaths $/ \mathrm{min}$. Rales presented to the midscapular region. A grade 3/6 mitral holosystolic murmur was audible. The chest $x$ ray showed bilateral pleural effusion, interstitial pulmonary oedema, but no cardiomegaly. The ECG showed sinusoidal tachycardia and left ventricular hypertrophy. The patient was given intravenous furosemide (frusemide) and glyceryl trinitrate. A transthoracic echocardiogram demonstrated elevated mean pressure gradient across the mitral valve $(27 \mathrm{~mm} \mathrm{Hg})$, mitral insufficiency, normal mean pressure gradient across the aortic valve, no aortic insufficiency, and normal left ventricular function (shortening fraction $40 \%$ ). Transoesophageal echocardiography confirmed severe mitral regurgitation extending into the pulmonary veins. The mitral regurgitation mechanism was identified; only one leaflet motion was visible and the characteristic shadow usually seen behind the leaflet in the closed position had disappeared (top) (arrow indicates lack of mask field; LA, left atrium). Moreover, cinefluoroscopy demonstrated leaflet escape (bottom). Two leaflets
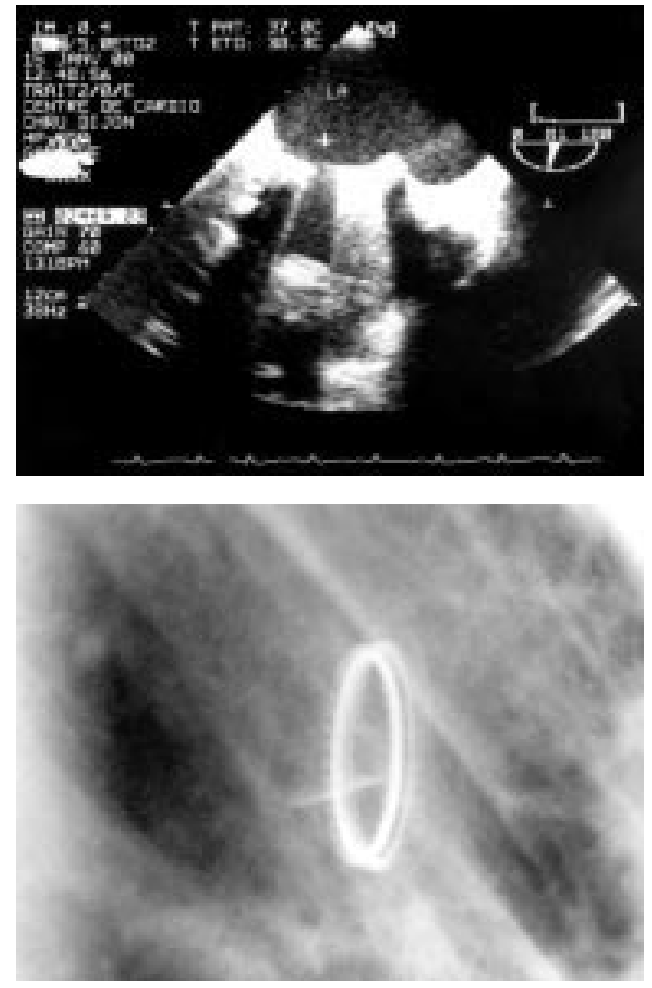

were visible at the aortic position and only one at the mitral position. The patient underwent emergency surgical removal of the mitral valve and had an uneventful recovery. The escaped leaflet was subsequently found in the terminal aortic bifurcation.

I L'HUILLIER J P MEUNIER S JAZAYERI 